\title{
Os estágios obrigatórios dos cursos de licenciatura e o Programa Residência Educacional: um estudo de caso
}

\author{
The compulsory stages of degree courses and Educational Residency \\ Program: a case study
}

\section{Las pasantías obligatorias de cursos de grado y el Programa de Residencia Educacional: un estudio de caso}

Recebido: 02/04/2014

Aprovado: 24/07/2014
Larissa Maira Malvestio ${ }^{1}$

Patrícia Aparecida Sousa Macedo²

A presente pesquisa apresenta a relação entre teoria e prática na formação de professores por meio de um estudo de caso. Para a realização do estudo acompanhou-se o estágio de uma estudante do ensino superior, do curso de Licenciatura em Química da Universidade de São Paulo, em uma escola estadual do município de Ribeirão Preto - SP. Essa pesquisa pretende analisar se o Programa Residência Educacional que possibilita que o aluno de graduação dos cursos de Licenciatura tenham a oportunidade de obter maior aproximação das práticas escolares do que os estágios obrigatórios. Proporciona a análise da teoria por parte do estagiário e a sua aplicação na prática, o que tem ou não possibilidade de ser aplicado no espaço escolar.

Descritores: Estágios; Internato não Médico; Prática profissional.

This research presents the relationship between theory and practice in teacher education through a case study. To conduct the study the internship of a Degree Course in Chemical Sciences student from the University of São Paulo, in a state school in the city of Ribeirão Preto - SP, Brazil. This research analyzes whether the Educational Residency Program enables the undergraduate students to have the opportunity to get closer to school practices than mandatory internships. It provides interns the analysis of theory and its implementation, pondering on what can or cannot being applied at school.

Descriptors: Internships; Nonmedical Internship; Professional practice.

Esta investigación presenta la relación entre la teoría y la práctica en la formación docente a través de un estudio de caso. Para realizar el estudio dio seguimiento a la etapa de la educación de una estudiante de ensiñanza superior, del curso de Licenciatura en Química de la Universidad de São Paulo, en una escuela pública en la ciudad de Ribeirão Preto - SP, Brasil. Esta investigación tiene como objetivo analizar si el Programa de Educación para la Vivienda permite a los estudiantes universitarios la oportunidad de conseguir las prácticas escolares más estrechos que las práctica supervisada. Proporciona el análisis de la teoría por el alumno y su aplicación en la práctica, que no tiene ninguna posibilidad de ser implementadas o en la escuela.

Descriptores: Pasantías; Internado no Médico; Práctica professional.

\footnotetext{
${ }^{1}$ Graduanda do Curso Licenciatura em Química da Universidade de São Paulo - Ribeirão Preto. Iala_rad@hotmail.com

${ }^{2}$ Geógrafa. Professora na Rede Estadual de Ensino do Estado de São Paulo. paty_asm@hotmail.com
} 


\section{INTRODUÇÃO}

$\mathrm{M}$ uito se tem questionado sobre os estágios supervisionados e a concepção da relação entre teoria e prática. 0 termo teoria é definido como "experiência, observação dos acontecimentos e também como iniciação para a ação, enquanto que o termo prática é definido como ação consciente"1. Uma maior preocupação para com o estágio supervisionado surgiu a partir da Lei $6.494 / 77^{2}$, que foi revogada pela Lei $11.788 / 08^{3}$, que compreende que o estágio complementa o ensino e a aprendizagem, sendo então um instrumento de integração e treinamento.

Á partir disso, muitas outras regulamentações foram implantadas na década de 1980 e inicio de 1990, apresentando os mesmos elementos, como Decreto no 87.497/82 Resolução SE 273/82, Resolução 208/86, Portaria Ministerial 399/89, passando o estágio a ser considerado relevante para a formação de professores $^{1}$. Os estágios são definidos como campo de conhecimento e eixo central nos cursos de licenciaturas, como uma atividade teórico-prática, de conhecimento, diálogo e intervenção na realidade, que permite a compreensão mais aprofundada da profissão de professor ${ }^{4}$.

Desta forma a Resolução CNE/CP $1 / 2002$, que institui as Diretrizes Curriculares Nacionais para Formação de Professores da Educação Básica, considera que a prática deve estar presente desde o inicio do curso, de forma a permear toda a formação do professor, sendo realizada em tempo e espaços específicos. 0 espaço escolar é usado para observar e refletir na resolução de situações problemas 5 . 0 estágio deve envolver processos que tenha a reflexão e orientação sobre as condições sociais da profissão de professor, principalmente em relação à competência e compromisso com a educação e sociedade ${ }^{6}$.

Visando aprimorar e complementar a formação dos futuros professores, no desenvolvimento de projetos educacionais com o intuito também de melhorar a educação básica do Estado de São Paulo, o Decreto no 57.978/12 instituiu o Programa Residência Educacional, como estágio complementar e/ou obrigatório, destinado aos alunos matriculados nos cursos superiores de Licenciatura7.

O programa é coordenado pela Secretaria de Estado da Educação de São Paulo, e conta com a colaboração da Fundação de Desenvolvimento Administrativo - FUNDAP e a Fundação de Desenvolvimento Educacional - FDE, que fiscalizam e alocam os estagiários.

Com isso, acompanhou-se o estágio de uma estudante do ensino superior, do curso de Licenciatura em Química da Universidade de São Paulo, em uma escola estadual do município de Ribeirão Preto-SP, procurando observar e analisar a relação entre teoria e prática. Tendo como objetivos verificar a proposta de estágio supervisionado, as leis que regem o Programa Residência Educacional e como a legislação ratifica o Programa à elucidação da prática docente.

\section{MÉTODO}

Esta é uma pesquisa de cunho qualitativo, do tipo estudo de caso realizado com uma aluna estagiária do Programa Residência Educacional de uma escola estadual e, contou com três momentos distintos que se inter-relacionaram em todo o processo da pesquisa.

O primeiro, de análise documental, foi realizado por meio de um levantamento das disciplinas pedagógicas trabalhadas durante a graduação do curso de Licenciatura em Química da Universidade de São Paulo, em que a aluna, sujeito da pesquisa, desenvolveu seus estudos. Desta forma buscou-se conhecer e analisar os conteúdos/teoria trabalhados em tais disciplinas. A escolha da aluna deu-se ao fato de ser a primeira a iniciar o programa Residência Educacional na escola em que foi feito o estágio e uma das únicas que o finalizou.

0 segundo procedimento, consistiu no acompanhamento da aluna em ação durante seu estágio, como por exemplo, aulas em que participou/assistiu, trabalhos realizados 
com a coordenação, com os alunos e com os espaços escolares. O acompanhamento da estagiária ocorreu uma vez por semana, no período da manhã, período em que a aluna permanecia na escola. As observações foram anotadas para posteriores análises. Esse acompanhamento aconteceu durante o ano letivo de 2013.

0 terceiro procedimento envolveu uma entrevista aberta, realizada no inicio do primeiro semestre de 2014 e elaborada com base nas observações durante o período de estágio da aluna, com o objetivo de comparar a eficácia da relação entre teoria e prática vivenciada pela estagiária. A entrevista foi gravada em áudio e, posteriormente, transcrita para a análise dos dados.

\section{RESULTADOS}

\section{Análise Documental das Disciplinas do Curso de Licenciatura em Química}

Seguindo os pressupostos teóricos discutidos neste trabalho, os estágios obrigatórios são considerados como complementares ao ensino e a aprendizagem, pela qual se dá sua integração entre a teoria trabalhada na universidade. Com isso, seguindo o proposto nos procedimentos metodológicos deste trabalho, foi feito o levantamento das disciplinas pedagógicas contidas no curso de Licenciatura em Química da Universidade de São Paulo em que a estagiária realiza sua formação.

Através deste levantamento, notou-se que as disciplinas relacionadas apenas à teoria pedagógica se iniciam a partir do segundo ano/terceiro período, de um curso com duração de cinco anos/10 períodos. As disciplinas que possuem estágios obrigatórios se iniciam a partir do terceiro ano/quinto período, conforme apresentado no Quadro 1.

A partir deste levantamento foram analisados os conteúdos dessas disciplinas e os conteúdos que são exigidos a serem trabalhados nos estágios obrigatórios. Este levantamento foi feito com o intuito de comparar o que está sendo trabalhado na teoria e o que está sendo cobrado nos estágios. Neste processo, observou-se que há relação entre a teoria e a prática exigida.

Quadro 1. Disciplinas da Licenciatura em Química relacionadas à Teoria Pedagógica. USP-RP, 2013.

\begin{tabular}{|c|c|c|}
\hline Ano & Período & Disciplinas \\
\hline $2^{0}$ & $3^{\circ}$ & $\begin{array}{l}\text { - Introdução aos Estudos } \\
\text { sobre a Educação }\end{array}$ \\
\hline $2^{\circ}$ & $4^{\circ} \mathrm{O}$ & $\begin{array}{l}\text { - Introdução aos Estudos } \\
\text { sobre a Educação em } \\
\text { Ciências }\end{array}$ \\
\hline $3^{0}$ & 50 & $\begin{array}{l}\text { - Política e Gestão } \\
\text { Educacional (possui } \\
\text { estágio obrigatório) } \\
\text { - Metodologia do Ensino de } \\
\text { Química I (possui estágio } \\
\text { obrigatório) }\end{array}$ \\
\hline $3^{0}$ & $6^{0}$ & $\begin{array}{l}\text { - Introdução à Língua } \\
\text { Brasileira de Sinais } \\
\text { - Psicologia Educacional } \\
\text { (possui } \\
\text { obrigatório) } \\
\text { - Metodologia do Ensino de } \\
\text { Química II (possui estágio } \\
\text { obrigatório) }\end{array}$ \\
\hline 40 & $7 \underline{0}$ & $\begin{array}{l}\text { - Metodologia Científica da } \\
\text { Pesquisa em Ensino de } \\
\text { Química e de Ciências } \\
\text { - Didática Geral I (possui } \\
\text { estágio obrigatório) } \\
\text { - Didática das Ciências } \\
\text { (possui } \\
\text { obrigatório) }\end{array}$ \\
\hline 40 & $8^{0}$ & $\begin{array}{l}\text { - Química para o Ensino } \\
\text { Médio I (possui estágio } \\
\text { obrigatório) }\end{array}$ \\
\hline 50 & 9o & $\begin{array}{l}\text { - Monografia em Ensino de } \\
\text { Química e de Ciências I } \\
\text { - Química Para o Ensino } \\
\text { Médio II (possui estágio } \\
\text { obrigatório) }\end{array}$ \\
\hline 50 & $10^{\mathrm{o}}$ & $\begin{array}{l}\text { - Monografia em Ensino de } \\
\text { Química e de Ciências II } \\
\text { - Atividades Integradas de } \\
\text { Estágios (possui estágio } \\
\text { obrigatório) } \\
\text { - Monografia } \\
\text { Supervisionada em Ensino } \\
\text { de Química e de Ciências }\end{array}$ \\
\hline
\end{tabular}


Acompanhamento da Estagiária em suas Práticas dentro do Espaço Escolar

O segundo procedimento diz respeito ao acompanhamento da aluna em suas práticas de estágio do Programa Residência Educacional. Esse acompanhamento foi feito uma vez por semana, observando e anotando suas atividades.

A estagiária fez o acompanhou o trabalho de um professor de Química da escola em que estagia, observava as ações do professor e o auxiliava em algumas atividades, como por exemplo, montagem e aplicação de listas de exercícios para os alunos, como forma de melhorar o entendimento dos conteúdos da disciplina e consequentemente na aplicação de monitorias para tirar duvidas dos alunos relacionados aos exercícios e a teoria da disciplina, acompanhamento na aplicação de provas e preenchimento de diários.

Fora das salas de aulas, a estagiária organizou todo o Laboratório de Ciências da escola, que se encontrava em estado desorganizado, separando reagentes vencidos e vidrarias quebradas, procurando dar um destino final aos mesmos. Foi observada também sua participação em atividades e projetos realizados pela escola, como também em Atividades de Trabalho Pedagógico Coletivo (ATPC), Conselhos e Planejamentos escolares, ou seja, a estagiária acompanhou e participou de todas as atividades e rotina de um professor.

\section{Dados obtidos em Entrevista com a Estagiária}

Tendo como base as anotações das observações, o terceiro procedimento envolveu a realização de uma entrevista com a estagiária a fim de analisar e entender como o Programa Residência Educacional complementou sua formação, assim como também o que o estágio obrigatório em comparação a este programa ainda deixa a desejar quando se trata da teoria versus prática.

De acordo com o dicionário online de português, estágio significa "período de estudos práticos, exigido dos candidatos ao exercício de certas profissões liberais: estágio pedagógico, aprendizagem, experiência". Segundo relatos da estagiária:

"Os estágios obrigatórios realizados durante a graduação, em sua grande parte são apenas de observação, apenas no ultimo ano é que temos a oportunidade de dar aula em forma de minicurso. O tempo de acompanhamento do professor é mínimo, de apenas um dia por semana".

Diferente do que foi observado nas práticas da aluna durante o estágio, o tempo de permanência da estagiária na escola pelo Programa é de 15 horas semanais, com a carga horária dividida entre os cinco dias da semana. Portanto, o contato com as atividades e rotina de um professor foi maior do que no estágio obrigatório. Em outra fala: "Durante o Programa Residência Educacional pude colocar a mão na massa, participar ativamente de todas as atividades de um professor no espaço escolar".

Com relação à teoria versus pratica, nas palavras da estagiária:

"O que vemos de teoria nas disciplinas da graduação muitas vezes não é possível aplicar nas práticas de estágios, pois não temos a liberdade que temos no Programa Residência Educacional de participar mais das atividades do professor".

Portanto, baseado em suas palavras, o Programa ofereceu mais oportunidades e entendimento das praticas da profissão.

\section{DISCUSSÃO}

De acordo com os resultados, se percebeu que a grade horária do curso de Licenciatura em Química possui uma ampla quantidade de disciplinas pedagógicas com o intuito de passar a teoria relacionada à profissão e atuação do professor e também uma grande carga horária de estágios, porém dividida nos três últimos anos da graduação, tornando pequeno o tempo de contato nas escolas por período.

Os estágios permitem que se tenha uma maior compreensão da profissão de ser professor, portanto a aproximação do aluno com o espaço escolar é importante para essa compreensão ${ }^{4}$, porém com o pouco contato por semana, essa aproximação se torna vaga nos estágios obrigatórios, pois a liberdade de 
contato e de ação dentro do espaço escolar é muito restrita.

Quando se fala sobre a teoria versus pratica, a teoria é a iniciação, a base para a ação, e a prática a própria ação, portanto as teorias aplicadas dentro das disciplinas dos cursos de Licenciatura devem não somente auxiliar, mas também serem possíveis de aplicação na prática ${ }^{1}$.

O Programa Residência Educacional teve seu nome inspirado na residência médica, com o objetivo de elevar os índices de desempenho nos processos de avaliação nas escolas consideradas prioritárias no Estado de São Paulo. Assim como a residência médica, o Programa procura auxiliar na complementação da formação dos futuros profissionais. A diferença está no fato de que a residência médica é considerada um programa de especialização, sendo necessário ser graduado, já o Programa de Residência Educacional é necessário ser graduando (no caso da formação médica, mais similar ao internato), fazendo parte da primeira formação do futuro profissional ${ }^{8}$.

Segundo os relatos da estagiária, pouca oportunidade se tem de poder aplicar as teorias aprendidas durante a graduação nas práticas dos estágios obrigatórios, diferentemente do que acontece no Programa Residência Educacional, onde a estagiária participa ativamente das ações e rotina do professor dentro do espaço escolar.

\section{CONCLUSÃo}

Esta pesquisa teve como limitação, o fato de se ter apenas uma única aluna e escola para se aplicar a pesquisa. Houve a dificuldade de não se poder comparar com outros alunos e outras escolas, sendo apresentado então, um estudo de caso.

Porém, mesmo com as limitações foi possível verificar que o Programa Residência Educacional possibilita ao aluno de graduação dos cursos de Licenciatura a oportunidade de obter maior aproximação das práticas escolares do que os estágios obrigatórios.
Proporcionou ainda, a análise da teoria por parte do estagiário e a sua aplicação na prática, o que tem ou não possibilidade de ser aplicado no espaço escolar, concluindo que o Programa vem atingindo seu objetivo de formar professores conscientes, competentes e compromissados com a educação.

\section{REFERÊNCIAS}

1. Dutra EF. Relação entre teoria e prática em configurações curriculares de cursos de licenciatura. VII Encontro Nacional de Pesquisa em Educação em Ciências - ENPEC. Florianópolis, 2009. Disponível em: http://posgrad.fae.ufmg.br/posgrad/viienpe c/pdfs/680.pdf Acesso em 13 abril 2014.

2. Brasil. Lei 6.494 de 7 de dezembro de 1977. Dispõe sobre os estágios de estudantes de estabelecimento de ensino superior e ensino profissionalizante do $2^{\mathrm{o}}$ Grau e Supletivo e dá outras providências. Disponível em: http://www.planalto.gov.br/ccivil_03/leis/L 6494.htm Acesso em: 15 abril 2014.

3. Brasil. Lei 11.788 de 25 de setembro de 2008. Dispõe sobre o estágio de estudantes. Disponível

em: http://www.planalto.gov.br/ccivil_03/_Ato2 007-2010/2008/Lei/L11788.htm\#art22

Acesso em 11 abril 2014.

4. Pimenta SG, Lima MSL. Estágio e docência. São Paulo: Cortez, 2004 (Coleção Docência em Formação: Série Saberes Pedagógicos). Disponível

em: http://www.cead.ufla.br/sisgap/cadSelecao /editais/outros/Estagio\%20e\%20docencia: \%20diferentes\%20concepcoesEdital062013 _2.pdf Acesso em 17 abril 2014.

5. Ministério da Educação (Br). Conselho Nacional de Educação. Parecer CNE/CP 09/2001 - Diretrizes Curriculares Nacionais para a Formação de Professores da Educação Básica, em nível superior, curso de licenciatura, de graduação plena. Brasília. Disponível em: http://portal.mec.gov.br/cne/arquivos/pdf/ 028.pdf Acesso em: 15 abril 2014.

6. Campos LML, Spazziani ML. O Estágio Curricular nos Cursos de Licenciatura: subsídios para a elaboração de uma proposta 
de diretrizes gerais para os estágios curriculares obrigatórios dos cursos de licenciatura da UNESP. Disponível em: http://iage.fclar.unesp.br/licenciaturas/PDF s/OEstagio.pdf Acesso em 16 abril 2014.

7. BRASIL. Decreto no 57.978 de 18 de abril de 2012. Institui o Programa Residência Educacional, no âmbito da Secretaria da Educação, e dá providências correlatas. Disponível em: http://governosp.jusbrasil.com.br/legislacao/1031716/dec reto-57978-12 Acesso em 17 de abril de 2014.
8. Ministério da Educação (Br). Conselho Nacional de Educação. Residência Médica. Disponível em: http://portal.mec.gov.br/index.php?option= com_content\&id=12263\&Itemid= 507 Acesso em 7 de Maio de 2014.

\section{CONTRIBUIÇÕES}

Larissa Maira Malvestio realizou o levantamento documental e a transcrição da entrevista.

Patrícia Aparecida Sousa Macedo desenvolveu o acompanhamento da estagiária e a realização da entrevista. A elaboração do manuscrito se deu por ambas as autoras. 